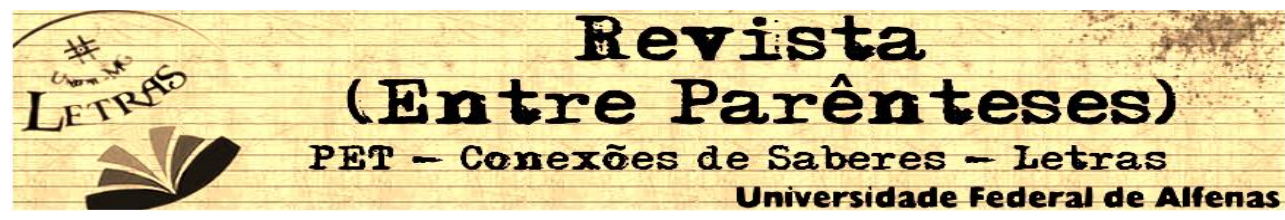

\title{
ANÁLISE SEMÂNTICA: OS PROCESSOS DE RESSIGNIFICAÇÃO EM LIVROS DIDÁTICOS
}

\author{
Fernanda Alvim de Oliveira ${ }^{1}$ \\ Universidade Federal de Alfenas \\ fernandaalvimareado@hotmail.com \\ Celso Ferrarezi Junior² \\ Universidade Federal de Alfenas \\ cferrarezij@superig.com.br
}

Resumo: A presente pesquisa foi realizada tendo como objeto livros didáticos utilizados em escolas públicas do estado de Minas Gerais. Visou à identificação de possíveis problemas de compreensão dos textos neles contidos que podem ocorrer com alunos nos processos de significação e ressignificação. Referenciada na "Semântica de Contextos e Cenários", a pesquisa parte da premissa de que uma mesma palavra ou sentença pode gerar compreensões diferentes pelo aluno, visto que o livro, na maioria das vezes, trabalha com um estilo linguístico distante do que o aluno está acostumado a utilizar no dia-a-dia.

Palavras-chave: 1. Compreensão. 2. Ressignificação. 3. Semântica de Contextos e Cenários.

Abstract: This research was conducted having as object textbooks used in public schools in the state of Minas Gerais. Aimed to identify possible problems of understanding of the texts contained therein that may occur with students in the processes of meaning and reframing. Referenced in the "Semantics of Contexts and Sceneries", the search starts from the premise that a single word or sentence can generate different understanding by the student, as the book, most of the time, works with a distant linguistic style that the student is accustomed to using day-to-day.

Key words: 1 . Understanding. 2. Reframing. 3 Semantics of Contexts and Sceneries.

\section{Introdução}

A pesquisa adentra a área da Linguística e é uma análise semântica sobre os processos de ressignificação em livros didáticos. De acordo com a leitura do livro "Semântica de Contextos e Cenários", sabemos que, muitas vezes, quando o

\footnotetext{
${ }_{1}^{1}$ Pesquisadora voluntária do Grupo de Pesquisas Linguísticas Descritivas, Teóricas e Aplicadas.

2 Professor Dr. Celso Ferrarezi Junior, Grupo de Pesquisas Linguísticas Descritivas, Teóricas e Aplicadas. 


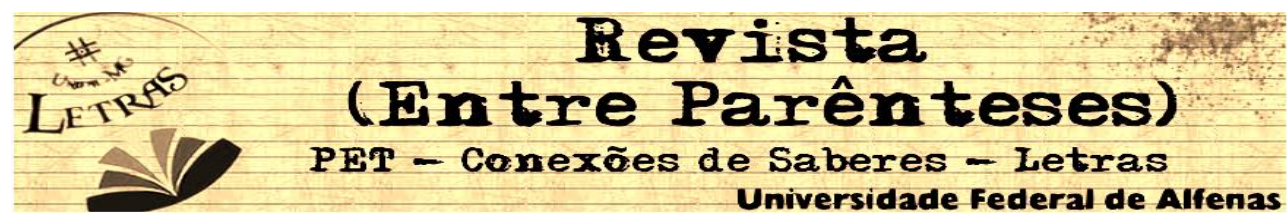

aprendiz ingressa no ambiente escolar, já possui uma gramática internalizada, pela qual é capaz de se comunicar perfeitamente no dia-a-dia. Mas, o livro didático trabalha uma língua distante da que o aluno está acostumado, pois um mesmo sinal utilizado, muitas vezes, tem um sentido no cotidiano do aluno e outro no da escola. Assim, não é incomum que, quando o aluno escuta determinada palavra, ele atribua sentido a ela de acordo com o que está acostumado a utilizar nas outras relações do dia-a-dia e não o sentido da escola.

Há pesquisas que apontam que esses problemas de compreensão podem gerar graves problemas de aprendizagem para os alunos, especialmente nas séries iniciais. Assim sendo, esta pesquisa se justifica na medida em que busca respostas para a questão dos processos de significação e ressignificação em ambiente escolar básico, permitindo vislumbrar diferentes aspectos do problema.

A pesquisa objetiva verificar se livros didáticos utilizados em escolas públicas de Minas Gerais apresentam problemas em relação aos processos de ressignificação de palavras ou expressões.

A Semântica Cultural, que é a área em que seguimos esta pesquisa, foi introduzida no país com o livro "Introdução a Semântica de Contextos e Cenários: de la langue à la vie" (Ferrarezi Jr., 2010). Esta obra aborda sobre como se dão as construções de sentidos e como se constitui a representatividade da língua. Tratando-se deste tema esta obra é essencial para o estudo de Semântica Cultural no Brasil e foi espelhada nela que a pesquisa caminhou.

\section{Referencial Teórico}

A pesquisa foi embasada na obra "Introdução à Semântica de Contextos e Cenários: de la langue à la vie" (FERRAREZI, 2010). Na Semântica de Contextos e Cenários - SCC o autor adota o conceito de que língua natural é um sistema de representação de mundo e seus eventos, que também foi adotado na nossa pesquisa: 


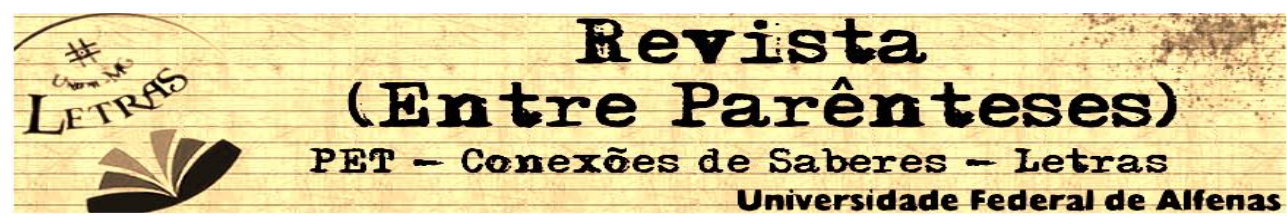

"A construção da SCC se apoia sobre uma ideia básica que, talvez, possa ser a melhor pista sobre seu enquadramento em uma corrente científica prévia - ao melhor gosto dos puristas e se isso é mesmo necessário... - que é a concepção de uma língua natural como um sistema de representação do mundo e de seus eventos." (FERRAREZI, 2010, p. 12)

Ferrarezi afirma que não se pode estudar o sentido na língua de maneira isolada, sempre se deve estudar o sentido quando estiver em pleno uso: "[...]uma vez que a língua só adquire sentido em uso, logo, tornando todo estudo do sentido, ou seja, toda Semântica, em um estudo semântico-pragmático lato sensu." (FERRAREZI, 2010, p. 16)

Portanto, Ferrarezi explica que o significado é orgânico, enquanto o sentido é de natureza cultural. E a língua opera para que haja compreensão:

"Trata-se de dois objetos plenamente distintos, embora relacionados. Um de natureza orgânica (o significado) e um de natureza cultural (o sentido). A língua opera com sentidos para que o cérebro humano possa operar com o significado, de forma a haver compreensão. Compreensão, portanto, só pode ser consistentemente entendida, neste enfoque, como 0 processo de operação com significados desencadeado a partir da operação com sentidos." (FERRAREZI, 2010, p.54)

O autor comenta, que diferente do que Katz afirmava, o significado não é um objeto de natureza linguística, e para comprovar usa três argumentos:

a. O significado independe do sinal e não está a ele vinculado de forma orgânica, podendo ser suscitado linguística ou não linguisticamente. Logo, não há nenhum argumento válido conhecido que justifique a ideia de que o significado é uma parte integrante dos sistemas linguísticos naturais;

b. O pensamento humano não é processado linguisticamente, mas em forma do que hoje ainda só podemos, por pura ignorância, chamar de "significações puras" ou, em última instância, de "significados";

c. A possibilidade de tradução entre línguas indica que não há uma relação determinativa entre o significado e o sistema linguístico que o representa, mas que qualquer significado é Revista (Entre Parênteses) - ISSN 2238-4502 


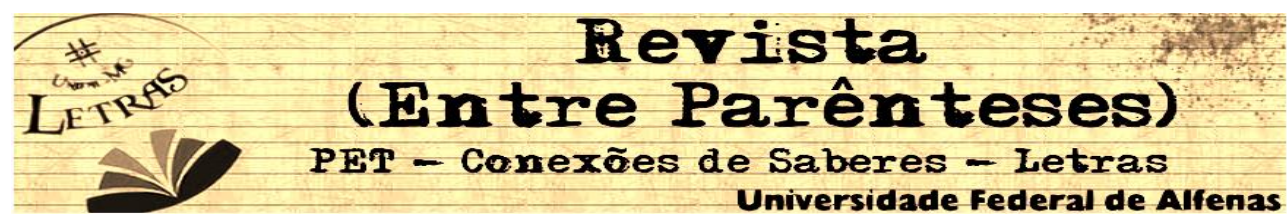

plenamente representável por qualquer sistema linguístico, independentemente das peculiaridades orgânicas desse sistema, embora haja nuanças de sentido que podem ser diferenciadas de língua para língua na busca da construção de um dado sentido. É bom observar que isso se dá, porém, muito mais em função do ambiente cultural em que a língua foi aperfeiçoada do que do sistema linguístico em si. (FERRAREZI, 2010, p. 53-54)

Tratando da formação da unidade de sentido na língua, Ferrarezi abandona a ideia de um signo linguístico binário do Curso de Linguística Geral, atribuída indevidamente a Saussure, e adota a formulação de Frege. O autor explica que Frege refere-se a "sinal" para representar a palavra (entre outras formas de sinalidade possíveis), e que afirma que este sinal está associado a um sentido. Esse sentido que é construído de acordo com a cultura e compartilhado pelos falantes de uma mesma língua permitindo a comunicação e entendimento:

Definido como ideia geral que os falantes de uma língua associam a um sinal qualquer a respeito de um objeto do mundo real (ou mundos possíveis, como assumimos aqui) seria o sentido o responsável pela possibilidade de comunicação entre os usuários de uma língua. (FERRAREZI, 2010, p.78)

Ferrarezi explica que a palavra não possui um sentido definido pela gramática:

Na verdade, a palavra não tem sentido nenhum definido pela gramática. A gramática de uma língua... é o conjunto de regras de operação da língua e, como regras de operação, ela não tem a característica - e o poder - de, sozinha, ser definidora de sentidos, uma vez que os sentidos são definidos por um processo muito mais complexo - que também inclui a gramática, mas não somente a ela. (FERRAREZI, 2010, p.7879)

O autor afirma que o que cabe estudar na Semântica não é o significado e sua natureza, mas as manifestações linguísticas do significado. Ainda ressalta que a Semântica não possui métodos para estudo do significado, mas apenas para estudo de suas manifestações linguísticas. Afirma que o sentido é construído por meio de 


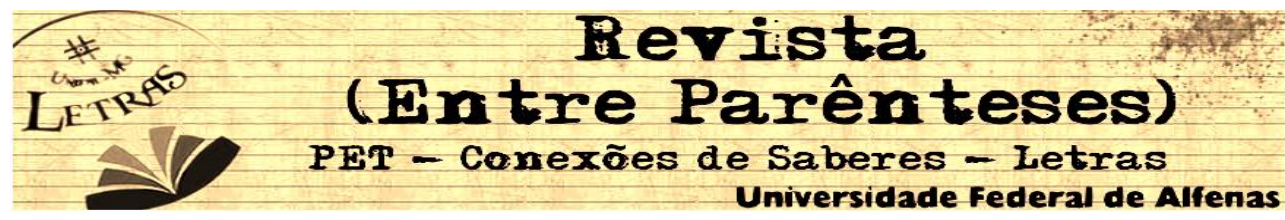

"traços de significado", construídos culturalmente e armazenados no cérebro de forma que haja a compreensão. (FERRAREZI, 2010, p. 63)

O sentido é, então, a ponte que faz a ligação entre o pensamento e o mundo, vinculando a expressão linguística ao referente representado e que, por isso, passa a ser o aspecto mais relevante a ser compreendido na constituição de uma língua natural. Tanto que o autor afirma que o sentido gera as bases necessárias para o falante construir a expressão, e não o contrário. Portanto, não é a língua construída que gera sentidos.

Ferrarezi sustenta a ideia de que a língua é norteada pelo Princípio da Representatividade:

Esse caráter representacional da língua se materializa no fato de que uma língua natural - ou os diversos fragmentos desta, cada um em sua vez, mais propriamente- pode "ser posta no lugar de" um mundo ou evento, permitindo a comunicação entre os interlocutores. (FERRAREZI, 2010, p.66)

Ferrarezi afirma que a língua não possui sentidos prévios e fixos. Os sentidos são construídos de acordo com o contexto e cenário:

Além disso, como uma forma de apresentação de algo, concebida e compartilhada socialmente, o sentido não pertence à organicidade da língua, mas Ihe é externo. É apenas associado aos sinais da língua no processo de representação ou pode sê-lo previamente em algum momento da aprendizagem dessa língua - e assim manifesto por ela. Esse fato de que, quando aprendemos uma língua, geralmente aprendemos um sentido costumeiro para cada sinal juntamente com o fato de que, quando usamos nossa língua, em função de que nossas repetitivas experiências de vida e de que há muitas coisas que costumeiramente associados a alguns mesmos sentidos, nos dão a sensação de que os sinais de uma língua têm sentidos prévios e fixos, previamente especializados, que não é verdade. (FERRAREZI, 2010, p.79)

Ferrarezi acredita na "composicionalidade do sentido", mas não na "composicionalidade do sentido da sentença", como muitas escolas de estudos semânticos adotam. Como ele cita: 


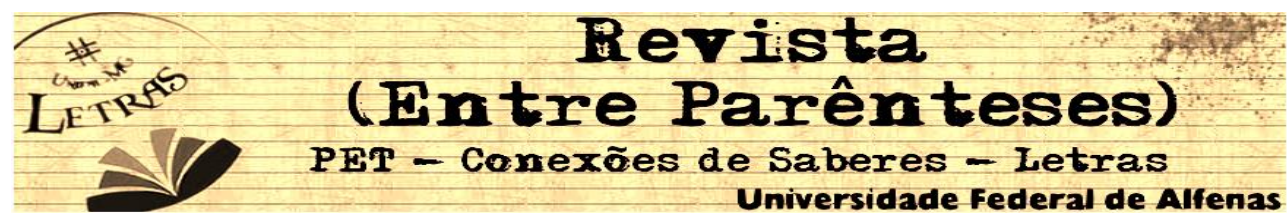

Cumpre ver que, para as unidades assumirem seus sentidos, ocorre um processo recursivo intenso em que as informações linguísticas e extralinguísticas são consideradas e reconsideradas, de forma cíclica, antes que se possa associar um sentido definido a uma unidade. Por isso é que, às vezes, damos início a um processo de interpretação com base em sentidos costumeiros, mas depois de alguma outra informação intra ou extralinguística, acabamos reconsiderando o sentido anteriormente pensado, o que tomamos inicialmente. $E$ interpretamos a sentença de forma diferente. (FERRAREZI, 2010, p.80)

E assim como um aluno quando identifica determinado sinal - que pela primeira vez está associado a um sentido diferente do que está acostumado - ele acaba associando o sinal ao sentido costumeiro, e não ao sentido adotado na escola. Mas com a explicação do professor, ele deveria retomar e interpretar a sentença de maneira diferente. O problema maior é que essa explicação sobre os sentidos de palavras do uso cotidiano dos alunos quase nunca ocorre. Portanto, como muito bem apresentado por Ferrarezi: "[...] se alguma relação há entre palavras e sentidos, essa relação é cultural, atribuída pelo habitus linguístico, por costume e não por propriedade das palavras ou dos sentidos." (FERRAREZI, 2010, p.81)

Ferrarezi explica que não só o português brasileiro mas, que todas as línguas não possuem palavras específicas para todos os sentidos. Portanto, uma só palavra pode possuir vários sentidos distintos: "Simplesmente, nenhuma língua tem palavras específicas para todos os sentidos que exprime, tendo que recorrer a construções ou adotar empréstimos - em que, muitas vezes, os sentidos costumeiros dos sinais não passam nem perto." (FERRAREZI, 2010, p.83)

Há lacunas no léxico porque a construção de sentidos nas culturas é muito mais dinâmica que a constituição do léxico de uma língua. Além disso, é muito mais econômico usar sinais que já conhecemos, mesmo que os associando a outros sentidos que não os seus sentidos costumeiros, do que ficar criando sinais para cada novo sentido que a cultura constrói. (FERRAREZI, 2010, p.83) 


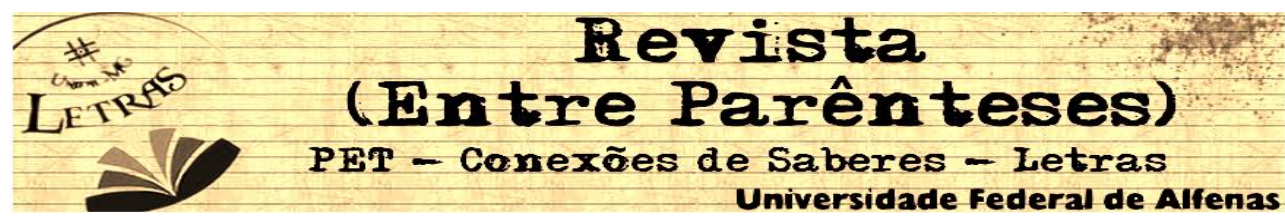

Como concluiu Ferrarezi, as palavras não possuem sentidos prévios e fixos. Por isso é necessário que se dê um complexo processo a que o autor chama de especialização de sentidos. A construção de sentido pode ser especializada por falantes de uma mesma língua ou até mesmo por grupos menores de indivíduos de uma dada cultura:

Essa construção se dá no âmbito da cultura de uma comunidade linguística, e a ela estão associados os mais diversos valores e construtos culturais. É no interior dessa cultura que o sinal-palavra é utilizado no lugar de, e por isso mesmo é no interior dessa cultura que se torna possível identificar qual sentido será a ele atribuído em cada enunciação, tanto pelo locutor (sentido pretendido), como pelo interlocutor (sentido reconstruído). (FERRAREZI, 2010, p. 85)

Ferrarezi afirma que é necessário que haja um fundo conversacional compartilhado de base cultural, para que ocorra o entendimento na comunicação entre os interlocutores:

[...]para que a utilização da língua no lugar de seja possível, é necessário que os interlocutores compartilhem um conjunto de conhecimentos. Como se diz tradicionalmente, é preciso que haja um fundo conversacional compartilhado. Mas, esse fundo conversacional compartilhado, que tem base cultural e é externo à língua, não consegue, por si só, garantir que:

a. Haja uma confluência entre os dados culturais dos diferentes agentes no ato comunicativo;

b. Que esses dados culturais, embora sejam socialmente construídos, sejam idênticos e, por isso;

c. Que haja obrigatoriamente o entendimento daquilo que se disse da forma como se pretendeu, logo;

d. Que haja comunicação bem sucedida em todos os casos. (FERRAREZI, 2010, p. 87)

$E$ isso acontece, segundo Ferrarezi, pois nem sempre o locutor e o interlocutor realizam a mesma especialização de sentido, sendo que as experiências pessoais e a maneira de entender são específicas de cada um, mesmo que possuam um fundo cultural compartilhado. Assim, em uma cultura, se constrói uma visão de mundo, e dentro dessa visão, cada pessoa cria a sua própria visão. 


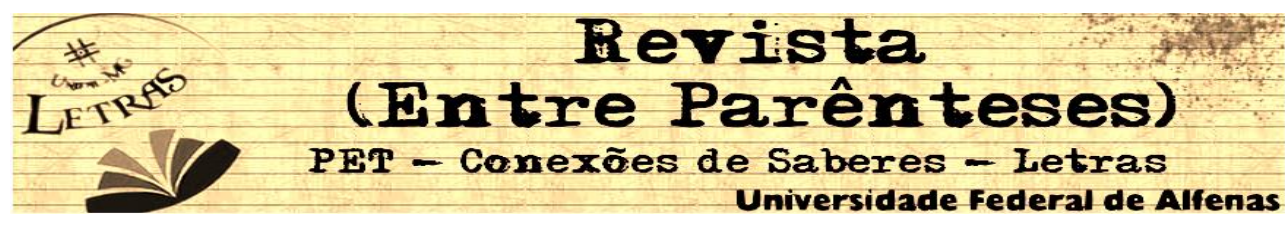

Daí, percebemos que uma língua é, de maneira geral, uma das mais importantes marcas identitárias de uma sociedade e, consequentemente, dos indivíduos que nela estão inseridos. A língua não é autônoma, pois ela se relaciona estritamente com a cultura influenciando, sendo influenciada e revelando construções e usos que os falantes dela fazem. Em outras palavras, a cultura é a base: a língua nasce dela e com ela, e nela sobrevive.

O autor ainda demonstra que a cultura é um elemento determinante, na mesma medida em que esse desvelamento é representativo dos valores mais próprios de uma comunidade:

[...] os sentidos se constroem culturalmente, e tudo o que é construído culturalmente é, obrigatoriamente, vinculado a valores culturais. Por isso mesmo, os sentidos expressam, além de suas associações referenciais, valores culturais e, assim, geram uma impressão desses valores nas mentes dos falantes. É a partir dessas impressões de valores que podemos construir um sentido que associamos a um sinal. (FERRAREZI, 2010, p. 123)

Ferrarezi afirma que o sentido que ao sinal se atribui se especializa no contexto e no cenário. Ou seja: é a partir da leitura do contexto e do cenário que os interlocutores obtêm as pistas necessárias para especializar o sentido de um sinal. Quando estamos utilizando a língua, estamos também ao mesmo tempo recuperando estas pistas para conseguir compreender o sentido:

A todo momento, estamos recuperando pistas colhidas ao longo do processo e reprocessando os sentidos antes atribuídos aos sinais-palavras, até chegarmos a uma compreensão que seja satisfatória. Isso ocorre a toda enunciação. [...] Quando lemos subvertemos um pouco esse processo. Na leitura - que não é um processo de origem natural como a fala - não há um cenário rico em pistas (como o cenário de uma conversa face-a-face) que possa nos servir de pano de fundo para processar as especializações dos sentidos. Então, temos que partir diretamente do contexto para construir esses cenários e reconstruir os prováveis sentidos dados aos sinais-palavras pelo autor. Por isso é que é mais fácil que leitores entendam (ou não entendam...) os textos de forma diferente daquela intencionada pelo autor, do que acontece em Revista (Entre Parênteses) - ISSN 2238-4502

Volume 1, Número 5, 2015 


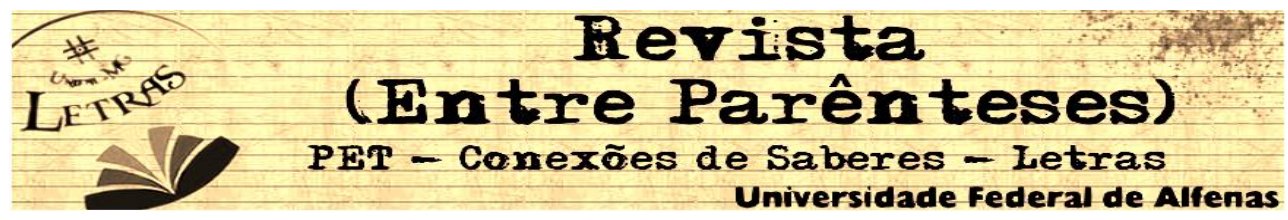

situação normal de diálogo. Isso porque o leitor, ao construir um texto, tinha um cenário em mente, e o leitor certamente terá outro quando o ler. ( FERRAREZI, 2010, p.128, 129)

Para esse autor, um dos fatos que dificultam a comunicação que ocorre na escrita é que "dificilmente, escritor e leitor compartilham um mesmo cenário, o que interfere definitivamente na especialização dos sentidos." (FERRAREZI, 2010, p. 276). Ainda complementa:

A escrita fornece palavras e partes de um contexto, mas não fornece cenários em que esses contextos sejam especializados e possam criar condições para a especialização dos sentidos das palavras. Por isso, é muito mais frequente a falha da comunicação na escrita do que na fala; por isso, é muitas vezes, mais fácil entender com exatidão o que se ouve do que aquilo que se lê. (FERRAREZI, 2010, p. 276)

Ferrarezi afirma que, quando um texto escrito é lido, o cenário é reconstruído - ou construído - na mente do leitor. E caso este leitor não tenha conhecimento do cenário original, para ele poder construir um sentido coerente, ele imaginará um cenário diferente do que o escritor idealizou originalmente:

Quando escrevo, tenho um conjunto de elementos relevantes em mente, que junto à minha história pessoal e à história daquela escritura, constituem um cenário bastante claro para mim, que fornece o fundo interpretativo do que estou escrevendo. Não raro, escrevemos algo que nos parece absolutamente claro, e que nossos leitores simplesmente não conseguem compreender. Não que esteja "mal escrito", nos sentidos gramatical ou estilístico, mas porque o leitor, ao reconstruir o sentido da escritura, faz uso de um cenário totalmente diferente do que eu utilizei ao produzir essa escritura. (FERRAREZI, 2010, p. 277, 278)

Para finalizar, aqui estão alguns pontos conclusivos e que estão relacionados a este trabalho 


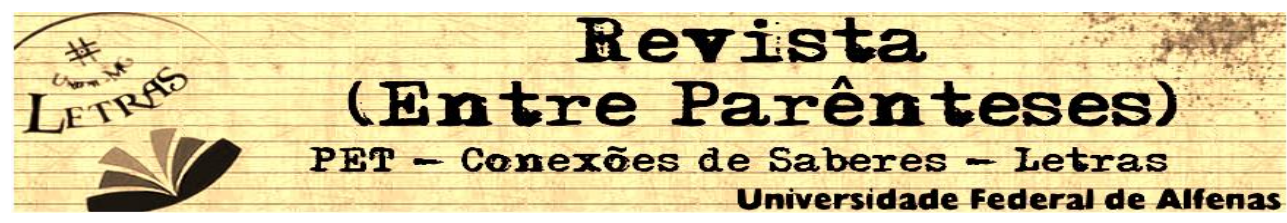

1. Um sistema linguístico pode ser considerado como um sistema de representação socializado e culturalmente determinado de mundos e de seus eventos;

2. logo, essa representação tem sempre caráter cultural e, portanto, é diretamente influenciada pela cultura em que esse sistema linguístico se insere;(pag 281)

8. muitos fenômenos analisados por correntes que consideram o sentido do sinal como uma propriedade fixa, isto é, que aceitam a existência do sentido literal, passam a ser analisados na SCC a partir de uma nova perspectiva que leva em conta três aspectos principais: a. o fato de que, embora os sinais de um sistema linguístico não possuam sentidos literais, é próprio das línguas que operam com um conjunto de sentidos costumeiros, de fundamento cultural, que aceleram e facilitam o processo de compreensão de uma representação construída em determinado contexto e cenário; $b$. os mecanismos que levam um sinal a especializar determinado sentido e não outro; c. a interferência de aspectos de ordem cultural nesses mecanismos, como, por exemplo, de categorias culturais que definem paradigmas que são representados. (FERRAREZI, 2010, p. 282- 283).

\section{A pesquisa}

A pesquisa utilizada foi a linguística de caráter semântico-cultural aplicada aos livros didáticos com avaliação qualitativa preliminar de resultados.

Nesta fase da pesquisa, apenas selecionamos alguns livros didáticos e, intentamos buscar palavras ou frases que poderiam ter um sentido costumeiro para os alunos, ou seja, palavras que sejam utilizadas cotidianamente pelos alunos com um sentido bem definido, mas que, na escola apresentassem outro sentido. Não foi realizada testagem de sentidos diretamente com os alunos como foi feito por Ocampo (2012). Isso caberá a uma segunda fase da pesquisa.

Os livros didáticos escolhidos são de séries do Fundamental I, utilizados em uma escola pública do estado de Minas Gerais, das seguintes disciplinas: Matemática, Português e Ciências. E como já era esperado, encontramos palavras e expressões que podem causar confusão aos alunos. 


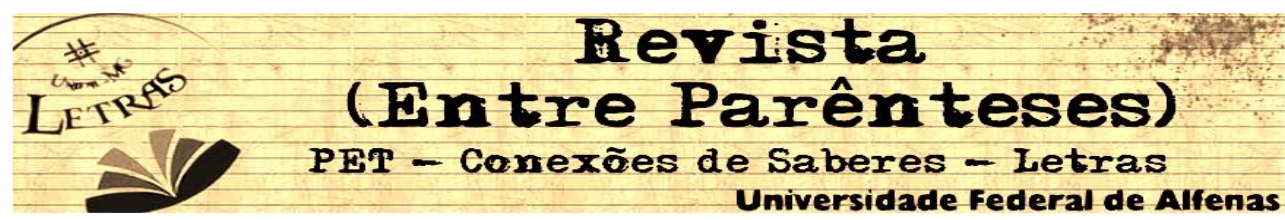

Vale ressaltar que os livros escolhidos são de séries em que os alunos estão no processo de aquisição de leitura e escrita, e é nessa fase que, caso não houver o entendimento do sentido das palavras ou expressões do livro didático, pode haver graves problemas de aprendizagem.

Aqui estão algumas palavras que encontramos, inseridas no contexto em que foram encontradas:

Sinal: Operação

Contexto: Que operação você faria para responder à pergunta de Pedro?

Sentido da escola: Cálculo

Sentido que pode ser atribuído pelo aluno: Operação médica; operação policial.

A palavra operação foi encontrada em um livro didático de matemática de $1^{\circ}$ ano, e esse sinal (operação) pode já ter aparecido na vida do aluno, no cotidiano, com o sentido de operação médica, operação policial. E não no sentido da escola, que é diferente do utilizado na vida do aluno. Entretanto, na escola essa palavra tem o sentido de calcular.

O problema, porém, como temos visto, não está nessa diferença de sentidos entre a vida do aluno e a escola, mas no fato de que a escola não explicita essa diferença, dando-a como subentendida.

\begin{tabular}{|l|}
\hline Sinal: Contar \\
\hline Contexto: Vamos cantar e também contar? \\
\hline Sentido da escola: Determinar o número, o valor, a quantidade. \\
\hline Sentido que pode ser atribuído pelo aluno: Narrar, referir. \\
\hline
\end{tabular}

Esta palavra foi encontrada no mesmo livro didático de matemática citado acima, e foi utilizada a palavra contar com o sentido de determinar o número, valor. 


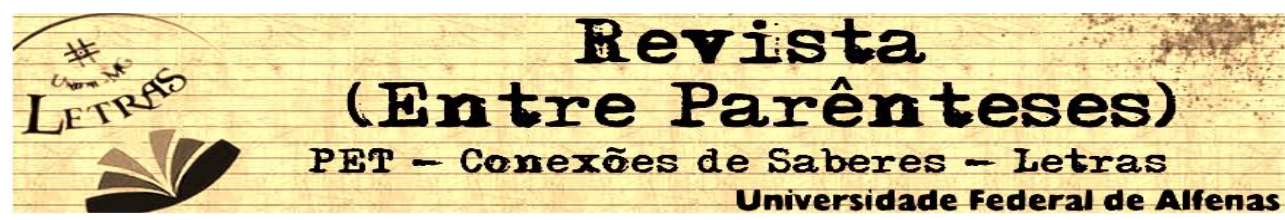

Mas o aluno, devido à idade, pode ter tido contato com esse sinal (contar) somente para se referir a uma narração, contar história, referir algo.

Sinal: Discuta

Contexto: Discuta com um colega e depois respondam.

Sentido da escola: Debater uma questão, emitir opinião.

Sentido que pode ser atribuído pelo aluno: Brigar, falar alto.

Esta palavra também encontrada no mesmo livro citado acima pode gerar uma confusão no aluno. Pois a única significação que ele pode ter tido em relação a esta palavra é no sentido de brigar, falar alto. Mas, na escola, ele teria que ter informações para proceder a uma ressignificação deste sinal que antes tinha só um sentido para ele, uma vez que, na escola, esta palavra tem o sentido de debater uma questão, emitir opinião.

\section{Sinal: Segredo}

Contexto: Descubra o segredo e continue a pintar o mosaico com as cores indicadas.

Sentido da escola: Mistério, enigma, resposta a uma questão.

Sentido que pode ser atribuído pelo aluno: O que não pode ser revelado, confidência.

Esta palavra citada acima, também pode gerar confusão ao estudante. Pois pode ter escutado apenas com o sentido costumeiro: algo que não pode ser revelado, confidência. Mas no ambiente escolar possui o sentido de mistério, enigma ou mesmo de resposta a uma questão.

\begin{tabular}{|l|}
\hline Sinal: Ligue \\
\hline Contexto: Ligue cada cachorro a sua casa \\
\hline Sentido da escola: Fazer uma união; ligar-se com alguém. \\
\hline
\end{tabular}




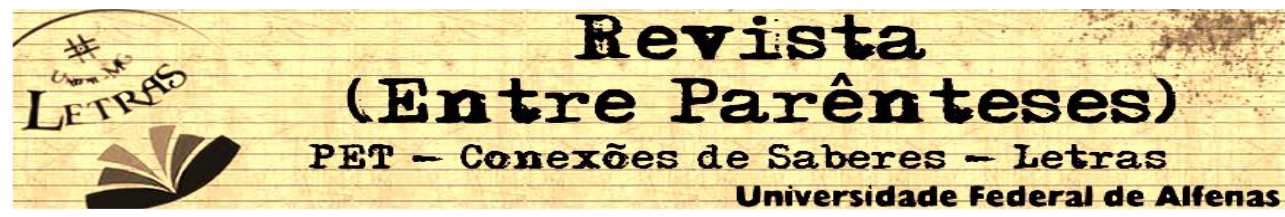

Sentido que pode ser atribuído pelo aluno: Telefonar.

A palavra ligar pode ser atribuída pelo aluno até o presente momento com o sentido de telefonar. Mas, neste contexto escolar, possui o sentido de fazer uma união, ligar-se a alguém.

Sinal: Representar

Contexto: Continue a pintar os quadradinhos para representar as quantidades indicadas.

Sentido da escola: Reproduzir pela pintura; representar.

Sentido que pode ser atribuído pelo aluno: Encenar

Essa palavra representar pode ter, no cotidiano do aluno, o sentido de encenar. Mas isso gera uma confusão, quando na escola, o sentido é de reproduzir pela pintura. Pois, nesta questão retirada do livro didático de matemática (o mesmo que foi utilizado para todos os exemplos até aqui) aparecem um numeral e vários quadradinhos na frente, e se pede para o aluno representar a quantidade indicada. No entanto, ele deve observar o número, e colorir a quantidade de quadrinhos que o número indica. Com certeza, gera confusão pelo aluno de séries iniciais, pois esta palavra neste contexto gerou confusão até para esta pesquisadora de IC.

\section{Sinal: Coluna}

Contexto: Pinte a quantidade pedida em cada coluna.

Sentido da escola: Cada uma das partes divididas verticalmente.

Sentido que pode ser atribuído pelo aluno: Coluna vertebral, coluna de construção civil.

A palavra "coluna" pode ter sido ouvida pelo aluno com o sentido de coluna vertebral ou coluna de construção civil. Mas, neste contexto da escola, pode ser 


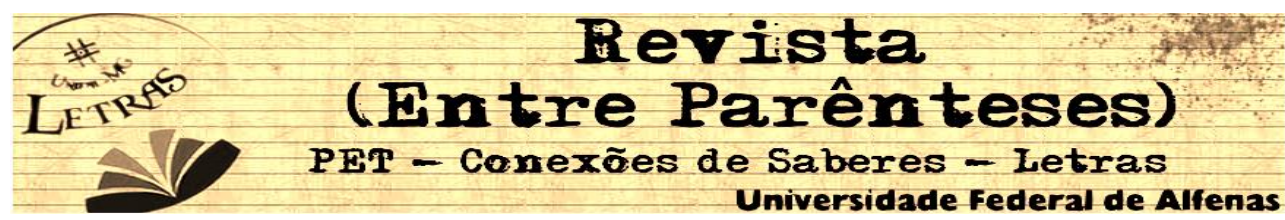

encontrada também com o sentido de "cada uma das partes divididas verticalmente". E isso pode gerar confusão pelo aluno.

Sinal: Diferença

Contexto: Qual é a diferença entre as quantidades de lápis de Ângela e de Antônio?

Sentido da escola: Operação matemática.

Sentido que pode ser atribuído pelo aluno: Uma coisa diferente da outra.

A palavra "diferença" pode ter sido ouvida pelo aluno para referenciar algo que é diferente de outro. Mas, na escola esta palavra é um termo técnico e está relacionada a uma operação matemática.

\section{Sinal: Espaço}

Contexto: Complete cada espaço com os números que faltam.

Sentido da escola: Extensão limitada.

Sentido que pode ser atribuído pelo aluno: Local destinado a certas atividades, espaço sideral, um espaço pessoal.

Neste exemplo, na escola, a palavra espaço pode referenciar várias coisas, como: os corpos celestes no espaço; intervalo de tempo, entre outros. Mas, neste contexto se encaixa o sentido de extensão limitada, ou seja, o lugar que o aluno deve preencher. Entretanto, o aluno pode atribuir o sentido de local.

Os exemplos citados até o presente momento são de livros de matemática de primeiro ano. A partir de agora, daremos início em exemplos encontrados em um livro de Português de primeiro ano:

\section{Sinal: Ordem}

Contexto: * Para que serve a ordem alfabética?

*Em que situações do dia a dia usamos essa ordem? 


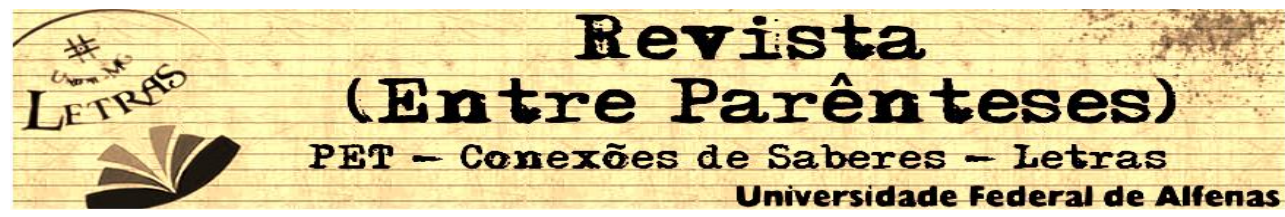

Sentido da escola: categoria; classe; escala.

Sentido que pode ser atribuído pelo aluno: comando; regra; mandado.

Neste caso, temos dois exemplos em que a palavra ordem relaciona-se a classe, escala. Mas, o estudante pode associar esta palavra com um comando. Pois, até então, pode ter só escutado esta palavra com o sentido de mandado, devido a sua idade.

Sinal: Móvel

Contexto: Recorte as letras do alfabeto móvel que estão nas páginas 211 a 217 e separe as letras que compõem o seu nome.

Sentido da escola: Movível.

Sentido que pode ser atribuído pelo aluno: Mobília.

Já que ao analisar esta situação, estamos nos colocando no lugar do aluno, acredito que um aluno nesta fase deve ter escutado esta palavra com o sentido "mobília", e não deve associar ao sentido de "algo movível". Portanto, pode gerar confusão ao aluno caso a professora não explique que, na escola e até em outros cenários, o aluno irá utilizar esta palavra com o sentido de algo que se pode mover. Isso permitiria que o aluno processasse uma ressignificação da palavra com a qual ele está acostumado o que, porém, raramente acontece.

\section{Sinal: Brincar}

Contexto: Vamos brincar de transformar palavras masculinas em femininas, como no primeiro exemplo?

Sentido da escola: Fazer atividades escolares.

Sentido que pode ser atribuído pelo aluno: Ação que desenvolve no ato de jogar; diversão.

Acreditando que, até então, o aluno referencia a palavra brincar como algo muito divertido, que the deixa contente, na maioria das vezes relacionado a jogos, Revista (Entre Parênteses) - ISSN 2238-4502

Volume 1, Número 5, 2015 


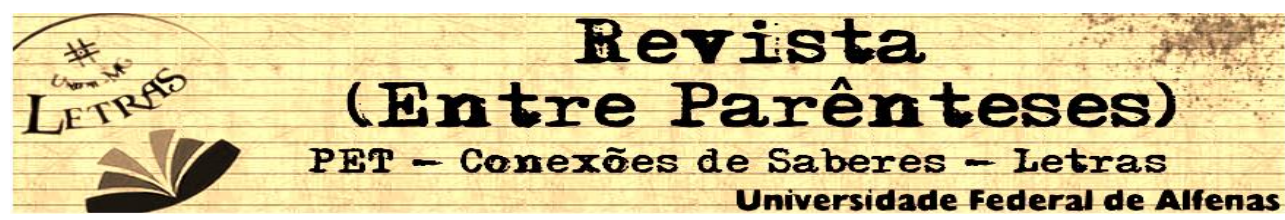

diversão. Neste contexto, o sentido parece estar totalmente "ao contrário" do que ele está acostumado a utilizar para essa palavra.

Sinal: Nome próprio

Contexto: Na sua classe, existem alguns nomes próprios escritos com Y?

Pesquise e registre-os abaixo.

Sentido da escola: Nome de pessoas, casas, ruas, países, etc.

Sentido que pode ser atribuído pelo aluno: nome de si mesmo

Neste contexto, o "nome próprio" relaciona-se a nome de pessoas da classe do estudante. Mas, a escola o utiliza também em relação a qualquer nome particular, e o faz como um termo técnico (nome próprio se opõe a nome comum) especialmente quando tenta ensinar o uso de grafemas maiúsculos. Porém, o aluno pode relacionar nome próprio apenas com o "nome de si mesmo".

A partir de agora os exemplos abordados são retirados de um livro didático da disciplina de Português de terceiro ano do Ensino Fundamental:

Sinal: Destino

Contexto: Escolham um destino

${ }^{\star}$ Formem cinco grupos

*Cada grupo escolhe uma região do Brasil

Sentido da escola: Direção; rumo.

Sentido que pode ser atribuído pelo aluno: Desígnio da vida.

Nesta questão, o que se pede para o aluno é que ele observe o mapa que está acima da questão e escolha uma das regiões do Brasil. Mas o aluno pode não ter escutado a palavra destino com o sentido de direção, rumo. Então, caso não seja bem explicitado, ele pode relacionar aos desígnios da vida. E isso fará uma confusão na cabeça do discente. 


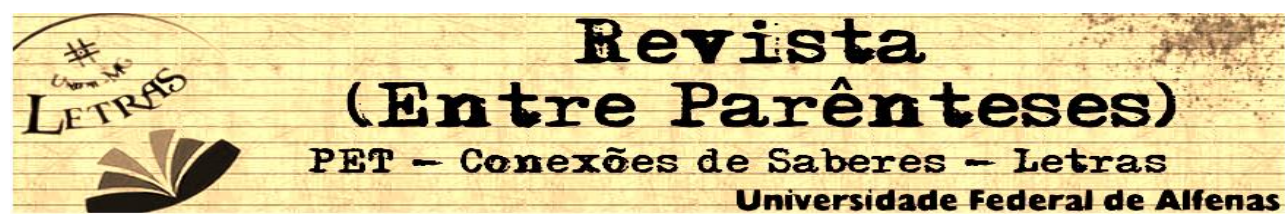

Sinal: Tempo

Contexto: Observe as ilustrações e responda no caderno.

O tempo é representado por qual ilustração?

Sentido da escola: Tempo em que se passa a história

Sentido que pode ser atribuído pelo aluno: Medida de duração

Neste contexto, o sinal tempo está relacionado com um texto e com algumas ilustrações que se referem à "noite", o tempo que se passa a história é a noite, sendo que a ilustração é um céu estrelado e uma lua. Mas, caso o aluno ainda não conheça este sentido, especialmente na idade em questão, acredito que o aluno associe o tempo com a medida de duração de algum evento ou com o sentido de uma determinada hora precisa, o que a ilustração não permite saber.

\section{Sinal: Proposta}

Contexto: Proposta de escrita

Sentido da escola: Utilizado em expressões como "atividade proposta"; "exercício indicado".

Sentido que pode ser atribuído pelo aluno: Fazer um acordo; apostar.

Como já foi houve em exemplos acima, este exemplo da palavra proposta mostra que, na escola, o sentido de proposta é diferente do que o aluno utiliza no cotidiano. Assim, caso o discente não consiga ressignificar esta palavra, ele poderá ter graves problemas para compreender o que e escola deseja dele.

O próximo exemplo foi retirado de um livro didático de Ciências de segundo ano do ensino fundamental:

\section{Sinal: Estado físico}

Contexto: Qual é o estado físico da água nos tecidos molhados?

Sentido da escola: Propriedades físicas.

Sentido que pode ser atribuído pelo aluno: Condição física de alguém. 


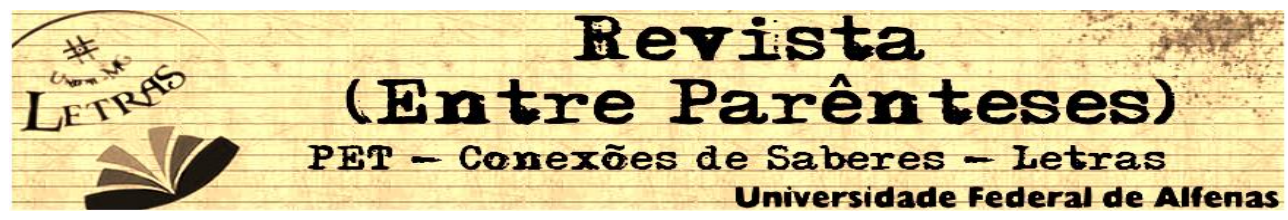

Neste exemplo, o aluno pode associar o estado físico, relacionado às Ciências (sentido que, provavelmente, nunca antes utilizou) com a ideia da condição física de uma pessoa, muito mais comum no coditiano. E então, caso não seja bem explicitado, o aluno pode relacionar a palavra ao sentido que, provavelmente, utiliza no cotidiano.

\section{Conclusão}

Por meio da pesquisa, pode-se concluir que:

1. há grande ocorrência de léxico especializado e não trabalhado como "tipicamente escolar" nos livros didáticos. Para que os sentidos sejam compreendidos no ambiente escolar, ele deve ser entendido no contexto do livro didático e no cenário, que é o da sala de aula. Sendo que, é dever do professor explicar o sentido utilizado na escola, e deixar bem claro para o aluno, principalmente das séries iniciais. E assim haverá o compartilhamento de saberes entre o aluno e a escola;

2. parte da incompreensão que os alunos apresentam, também em Minas Gerais, do conteúdo escolar pode (como atestou Ocampo, 2012 para Rondônia) estar vinculada a processos de ressignificação incorretamente realizados ou, simplesmente, não realizados.

3. como foi abordado, em cada cultura pode haver um sentido diferente para o mesmo sinal. Então não pode ser distribuído um mesmo livro didático, com um texto unificado, para o país inteiro, como já afirmou Ferrarezi, pois os sinais que são utilizados com um sentido em determinado lugar, em outro podem não ter o mesmo sentido.

\section{Referências bibliográficas}




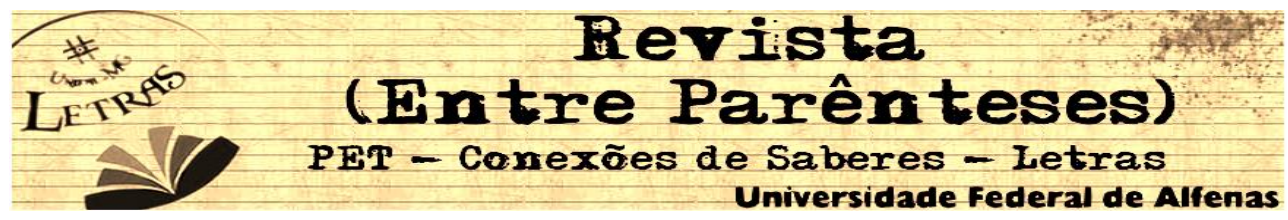

FERRAREZI Jr., Celso. Introdução à Semântica de Contextos e Cenários: de la langue à la vie. Campinas, SP: Mercado de Letras, 2010.

OCAMPO, Fabíola Ferreira; FERRAREZI Jr, Celso (Org) Os Sentidos da Escola: Os Processos de Ressignificação e a Aprendizagem em Ambiente Escolar, Porto Velho, 2011.

FERRAREZI Jr., Celso. Os sentidos da escola: o processo de re-significação e a aprendizagem em ambiente escolar. In: Línguas, Linguagens e Culturas Amazônicas. São Paulo: Pedro e João Editores/ Porto Velho: EDUFRO, 2009.

Projeto Buriti: português/ organizadora Editora Moderna; obra coletiva concebida, desenvolvida e produzida pela Editora Moderna; editora responsável Marisa Martins Sanchez. -1. Ed. - São Paulo : Moderna, 2007.

VAZ, Débora. Português: escrita, leitura e oralidade / VAZ, Débora; MORAES, Elody Nunes; VELIAGO, Rosângela. - 1. Ed. - São Paulo: Moderna, 2011.

BONJORNO, José Roberto. Matemática pode contar comigo: alfabetização matemática, $1^{\circ}$ ano / BONJORNO, José Roberto; BONJORNO, Regina de Fátima Souza Azenha; GUSMÃO, Tânia Cristina Rocha Silva. -1. Ed. São Paulo: FTD, 2011.

PASSOS, Marinez Meneghello. De olho no futuro: matemática: novo/ MENEGHELLO, Marinez, PASSOS, Angela; São Paulo: Quinteto Editorial, 2005. (Coleção de olho no futuro matemática)

Projeto Buriti: ciências/ organizadora. Editora Moderna; obra coletiva concebida, desencolvida e produzida pela Editora Moderna; editora responsável Lia Monguilhott Bezerra. - 2. Ed. - São Paulo : Moderna, 2011. 